\title{
Healthy and Unhealthy Dietary Patterns are related to Lipid Parameters in Patients with Type 2 Diabetes Mellitus
}

\section{Noorshahi $\mathrm{N}^{1}$, Sotoudeh $\mathrm{G}^{2}$, Djalali $\mathrm{M}^{1}$, Eshraghian $\mathrm{MR}^{3}$, Karimi $\mathrm{Z}^{4}$, Mirzaei $\mathrm{K}^{1}$, Javadi $\mathrm{F}^{5}$, Basiri $\mathrm{MG}^{1}$, Nikbazm $\mathrm{R}^{1}$, Rafiee $\mathrm{M}^{1}$ and Koohdani $\mathrm{F}^{* 1,6}$}

\author{
${ }^{1}$ Department of Cellular and Molecular Nutrition, School of Nutritional Sciences and Dietetics, Tehran University of \\ Medical Sciences, Tehran, Iran \\ ${ }^{2}$ Department of Community Nutrition, School of Nutritional Sciences and Dietetics, Tehran University of Medical \\ Sciences, Tehran, Iran \\ ${ }^{3}$ Department of Biostatistics and Epidemiology, School of Public Health, Tehran University of Medical Sciences, \\ Tehran, Iran \\ ${ }^{4}$ School of Nutrition, Shahid Beheshti University of Medical Sciences, Tehran, Iran \\ ${ }^{5}$ Department of Clinical Nutrition, School of Nutritional Sciences and Dietetics, Tehran University of Medical \\ Sciences, Tehran, Iran \\ ${ }^{6}$ Diabetes Research Center, Endocrinology and Metabolism Clinical Sciences Institute, Tehran University of Medical \\ Sciences, Tehran, Iran
}

${ }^{*}$ Corresponding author: Koohdani F, Department of Cellular and Molecular Nutrition, School of Nutritional Sciences and Dietetics, Tehran University of Medical Sciences, Tehran, Iran and Diabetes Research Center, Endocrinology and Metabolism Clinical Sciences Institute, Tehran University of Medical Sciences, Tehran, Iran, E-mail: fkoohdan@sina.tums.ac.ir

Citation: Noorshahi N, Sotoudeh G, Djalali M, Eshraghian MR, Karimi Z, et al. (2016) Healthy and Unhealthy Dietary Patterns are related to Lipid Parameters in Patients with Type 2 Diabetes Mellitus. J Nutr Health Sci 3(1): 103. doi: 10.15744/2393-9060.3.103

Received Date: December 09, 2015 Accepted Date: February 22, 2016 Published Date: February 24, 2016

\footnotetext{
Abstract

Objective: The effects of a single food or nutrient on disease may be insufficient and poor, but the cumulative effect is detectable. The purpose of this study is to determine the relationship between dietary patterns and lipid parameters in patients with type 2 diabetes.

Materials and Methods: 740 diabetic patients from different districts of Tehran participated in this cross sectional study. Dietary patterns were identified by factor analysis. Univariable and multivariable logistic regression models were used to determine odds ratio of dyslipidemia in relation to dietary patterns.

Results: Two major dietary patterns were identified: Healthy dietary pattern (high intake of vegetables, tomatoes, fruits, fish, olives, beans) and Unhealthy dietary pattern (high intake of simple and refined carbohydrate, processed meat, industrial juices, high-fat dairy products, butter, sweets and desserts, eggs, snacks and sugar). After adjusting the confounders, Healthy dietary pattern reduced odds for hypertriglyceridemia by $49 \%$. Also the chance of increased HDL-c in the highest quartile of Healthy dietary pattern was 2.4 times more than those in the lowest.

Conclusion: Healthy dietary pattern is associated with low levels of LDL-c and high HDL-c levels. No association was found between Unhealthy patterns with lipid profile.

Keywords: Dietary pattern; Dyslipidemia; Factor analysis; Type 2 diabetes

List of abbreviation: FFQ: Food Frequency Questionnaire; HDL-c: High Density Lipoprotein cholesterol; LDL-c: Low Density Lipoprotein cholesterol; CVD: Cardiovascular disease; BMI: Body mass index; PCA: Principal component analysis; KMO: KaiserMeyer-Olkin; BTS: Bartlett Test of Sphericity; ANOVA: Analysis of variance; OR: Odd Ratio
} 


\section{Introduction}

Today diabetes is a major health problem in the world due to its high prevalence [1]. Lipid abnormalities (dyslipidemia) are one of diabetes complications which led to increased prevalence of cardiovascular disease (CVD) in these patients [2]. Studies have suggested that impaired glucose regardless of its severity increases the risk of cardiovascular disease [3,4]. Studies have shown a strong association between hypercholesterolemia and incidence of cardiovascular diseases and its mortality rate, so that $1 \mathrm{mg} / \mathrm{dl}$ reduction in LDL-c decreased 1-2\% relative risk of cardiovascular disease. Several factors affect the amount and composition of plasma lipoproteins $[5,6]$.

Nutrition is one of the most important environmental factors in initiation and treatment of diabetes mellitus [7]. A healthy diet may reduce risk of dyslipidemia and its associated disorders [8]. Most studies on the relationship between diabetic diet and lipid profile have been focused on single nutrients or foods [9-13]. Since the relationship between diet and disease is very complicated, it has been suggested that using dietary pattern analysis or whole diet study, instead of analysis of a particular nutrient. Factor analysis $[14,15]$ could eliminate the concerns relating to confounding factors and interactions between food and nutrient and taking nutritional behaviors. It could provide more detailed information about the relationship between diet and lipid profile as a main risk factor of cardiovascular diseases in diabetic patients [2,16-24].

Lipid profiles have been studied as a part of metabolic syndrome components [3,4,12,22,23,25-36]. Most of these studies are held in western countries [15,21-23,26,32-34,37]. Some studies have revealed the association between metabolic syndrome and dietary patterns suggesting that certain dietary patterns characterized by low total and saturated fat intake and high fruit, vegetable, whole grain, and low-fat dairy intake are protective against metabolic syndrome or its components $[23,25,26,38]$. The studies on Asian population have also shown positive effects of dietary patterns characterized by high consumption of vegetables, fruits, whole grains and fish on the reduction risk of having high cholesterol or/and triglyceride [27-30,39]. On the other hands, the dietary patterns rich in sugar, sweets and refined grains increase the risk of having low HDL-c and/or high triglyceride [27,28,30,39,40]. According to our knowledge there is no study which investigated the association between lipid abnormalities and dietary patterns singly in diabetic patients.

As more educational programs that cover diabetic patients, having more healthier dietary pattern is expected compared with healthy people. But given the high prevalence of dyslipidemia in patients with type 2 diabetes, this study aimed to identify the association between major Iranian type 2 diabetes patients' dietary patterns and dyslipidemia.

\section{Materials and Methods}

\section{Subjects}

This cross-sectional study was conducted from September 2011 to June 2012. Data were collected from 768 type 2 diabetic patients (299 men and 441 women) aged 35 to 65 years with a random sampling of patients referred to Diabetes Centers in Tehran such as Iranian Diabetes Society, Gabric Diabetes Association, health centers, Specific Disease Center in East of Tehran and health houses. After providing written and oral comments on the objective and methodology of the study, written informed consent was obtained from participants. Individuals under 35 or more than 65 years, insulin users, pregnant or lactating women and consumers of alcohol 24 hours before the examination were excluded.

\section{General and anthropometric assessment}

Information regarding the required variables such as age, education, marital status, medical history and medication history was collected using pre-tested questionnaires. Height and weight were measured with minimum clothing, without shoes by using Seca Falcon scale and Seca stadiometer and according to standard protocols. Height and weight measurement were recorded with an accuracy of $100 \mathrm{~g}$ and $0.5 \mathrm{~cm}$ [41] respectively. Body mass index (BMI) was calculated as weight $(\mathrm{kg}) / \mathrm{height}^{2}(\mathrm{~m})$.

\section{Dietary assessment}

Usual dietary intake during the past year was measured using a valid and reliable semi quantitative food frequency questionnaire which included 148 food items [42]. The FFQ consisted of a list of foods and a standard serving size for each (Willett format) [43]. Participants were interviewed face to face by trained nutrition experts. The subjects were asked to report the frequency of consumption of each food item according to the standard size and based on option per day, week, month, or year. The values for each food converted to grams per day using Handbook of domestic scale [44], finally the equivalent gram of each food item consumption in terms of each person per day was obtained. To assess the energy and nutrient contents Nutritionist III software (version 7.0; N Squared Computing), designed to evaluate of Iranian foods, was utilized. Individuals who did not respond to more than 50 percent (70 food items) of food frequency questionnaire or either their total energy intake was less or more than 3 standard deviations of mean energy were excluded $(n=28)$. Final analysis was performed on 740 patients. 
According to the similarity of food items, thirty-four food groups were created (Table 1). Dietary patterns determined by exploratory factor analysis. Extracted food groups were entered into the factor analysis and a principal components method was used to determine dietary patterns. Orthogonal varimax rotation method was used to generate a simple and distinction matrix for identifying major dietary patterns, based on number of food groups. The eigenvalue and Scree plot was used to determine the number of dietary patterns. The Scree plot is a plot of the eigenvalues of derived factors. The point shift in action on Scree plot was used to determine the number of dietary patterns. The factor score for each pattern was calculated by summing intakes of food groups weighted by their factor score matrix. The derived dietary patterns were labeled on the basis of our interpretation of the data and of the earlier literature.

\begin{tabular}{|c|c|}
\hline Food Groups & Food Items \\
\hline Processed meat & Sausages \\
\hline Red meat & Beef, lamb, ground beef, mince, burgers \\
\hline Meat offal & $\begin{array}{l}\text { Heart, liver and kidney, tongue and brain, head, crus and shin, stomach and } \\
\text { abomasums }\end{array}$ \\
\hline Fish & Any fish, Tuna fish \\
\hline Poultry & Chicken meat \\
\hline Egg & Local and non-local eggs \\
\hline Butter & Butter \\
\hline Margarine & Margarine \\
\hline Low-fat dairy & Low-fat milk, skim milk, low fat yogurt, pasteurized cheese \\
\hline High-fat dairy & $\begin{array}{l}\text { High-fat milk, High-fat yogurt, creamy yogurt, creamy cheese, chocolate } \\
\text { milk, cream, traditional and non-traditional ice cream }\end{array}$ \\
\hline Tea & Tea \\
\hline Coffee & Coffee and espresso \\
\hline Fruits & $\begin{array}{l}\text { cantaloupe, watermelon, melon, prunes, apple, apricot, yellow plum, red } \\
\text { plum, sweet cherry, cherry, nectarine, peach, pear, fig, orange, tangerine, } \\
\text { dates, grapes, kiwi, pomegranate, strawberry, banana, sweet lime, lemon, } \\
\text { grapefruit, persimmons, fresh berries, raisins, dried fruits(figs, berries, peach, } \\
\text { apricot), orange juice, apple juice, cantaloupe juice, lemon juice }\end{array}$ \\
\hline Industrial Juice & industrial fruit juices \\
\hline Cabbages & any kind of cabbages \\
\hline Yellow vegetables & carrots, carrot juice \\
\hline Tomato & $\begin{array}{l}\text { fresh tomato, tomato products prepared from tomato (red sauce, tomato } \\
\text { paste) }\end{array}$ \\
\hline Green leafy vegetables & spinach, lettuce \\
\hline Other vegetables & $\begin{array}{l}\text { cucumber, eggplant, raw or fried onions, fresh herbs, vegetable stew, veg- } \\
\text { etable soup, green beans, pea, squash, stewed pumpkin, mushrooms, garlic, } \\
\text { peppers, capsicum, turnips, celery, mushrooms, Maize and corn }\end{array}$ \\
\hline Beans & dried beans, peas, split peas, mung, soybeans, lentils, other \\
\hline Potato & Potato \\
\hline Fried Potato & fried potato \\
\hline Whole grains & local breads, bran bread, cereal, oats, baked barley \\
\hline Refined grains & baguettes, rice, pasta, vermicelli, noodles, wheat flour \\
\hline Snacks & cookies, crackers, snack, chips \\
\hline Nuts & peanuts, almonds, walnuts, pistachios, hazelnuts, any seeds \\
\hline Olive & olives, olive oil \\
\hline Sweets and Desserts & cakes, cookies, sweets, creamy sweets \\
\hline Pickles & any kind of pickles \\
\hline Spices & Spices \\
\hline Solid oils & Solid animal oil, solid vegetable oil , mayonnaise, beef tallow \\
\hline Other oils & Any type of oil(except olive oil) \\
\hline Sugar & sugar, Tamarisk, filing, candies, sweet, chocolate, honey, jams \\
\hline Soft drinks & Soft drink \\
\hline
\end{tabular}

Table 1: Grouped food items to use in factor analysis to identify dietary patterns 
To determine the adequacy of the sample, Kaiser-Meyer-Olkin (KMO) test and to determine the relationship between variables, Bartlett Test of Sphericity (BTS) was utilized. KMO and BTS for this study were 0.690 and 0.001 respectively. Given the correlations between the data, food groups with factor loadings over 0.3 were considered as making a significant contribution to the pattern. Two dietary patterns which have higher percent of variance in our population were chosen. Subjects were categorized into four groups (quartiles) in terms of dietary pattern scores. Each quartile includes approximately $25 \%$ of population.

\section{Biochemical evaluation}

12-14 h fasting venous blood samples were taken in order to measure serum lipids [45]. Total cholesterol and triglycerides were measured by enzymatic methods using Pars Azmoon kits, Pars Azmoon Inc., Tehran, Iran. LDL-c and HDL-c levels were assayed according to lab kit instructions, in qualified lab certified ISO 9002. Lipid profiles of the patients were divided into two groups of normal or abnormal according to the Standards of Medical Care in Diabetes (Diabetes Care) of the Diabetes Association of America, 2014 [46].

\section{Physical activity}

Daily physical activity evaluated in terms of metabolic equivalent $\times$ hours per day (MET.h.day) by a physical activity questionnaire which has been developed in Europe in previous studies and its validity has been confirmed [47]. Reliability and validity of this questionnaire have been confirmed by Kelishadi, et al. study in Iran [48].

\section{Statistical Analysis}

General characteristics of participants in quartiles of dietary patterns were compared using one-way analysis of variance (ANOVA) for quantitative variables and chi-square test for qualitative variables. Binary logistic regression analysis in multiple models was used to test dietary patterns association with dyslipidemia, with adjustment for different variables such as age, sex, family history of diabetes, duration of diabetes, BMI, physical activity, use of lipid-lowering drugs and energy intake. IBM SPSS Statistics version 21 was used for all steps of the analysis. All p values were based on two-sided tests and compared with significance level of 0.05 .

\section{Result}

Food grouping was performed according to Table 1 in order to be used in factor analysis to identify dietary patterns. Using factor analysis, two major dietary patterns in the study population were identified which are presented in Table 2. Healthy dietary pattern was high in vegetables, cabbages, tomatoes, yellow vegetables, fruits, fish, olives, beans. The second, Unhealthy food pattern was high in sugar, soft drinks, sweets and desserts, industrial juices, high-fat dairy products, butter, processed meat, eggs, refined grains and snacks. Altogether these two major dietary patterns form $15.7 \%$ of total variance.

\begin{tabular}{|l|l|l|l|}
\hline Healthy food pattern & & Unhealthy food pattern & \\
\hline Food Groups & & Food Groups & \\
\hline Other vegetables & 0.765 & Industrial Juice & 0.585 \\
\hline Cabbages & 0.579 & Processed meats & 0.542 \\
\hline Yellow vegetables & 0.574 & Refined grains & 0.527 \\
\hline Tomato & 0.546 & Soft drinks & 0.505 \\
\hline Green leafy vegetables & 0.516 & Sweets and Desserts & 0.500 \\
\hline Fruits & 0.503 & Butter & 0.413 \\
\hline Fish & 0.387 & High-fat dairy & 0.365 \\
\hline Olive & 0.359 & Snacks & 0.355 \\
\hline Beans & 0.306 & Egg & 0.329 \\
\hline & & Fried Potato & 0.328 \\
\hline & & Sugar & 0.318 \\
\hline & & Meat offal & 0.317 \\
\hline Percent of variance & 9.8 & Percent of variance & 6.3 \\
\hline
\end{tabular}

${ }^{\star}$ Load factor less than 0.3 are omitted to simplify the table

$\dagger$ Kaiser's Measure of Sampling Adequacy (MSA) $=0.690$, Bartlett's test of sphericity $=<0.001$

Table 2: Load factor of food groups for 2 major predominant dietary patterns $\dagger^{*}$

Table 3 shows some general characteristics of participants in this study based on the presence or absence of lipid disorders. The interesting results are, those with normal triglyceride levels had a lower daily energy $(\mathrm{p}<0.05)$ and also lower lipid lowering drugs intake $(\mathrm{p}<0.05)$ compared with those with hyper triglyceridemia. Individuals with normal LDL-c levels have higher incidence of CVD histories $(\mathrm{p}<0.001)$. However higher level of LDL-c was observed in people with family history of diabetes. Patients with normal HDL-c concentration have lower percent of alcohol consumption $(\mathrm{p}<0.05)$ and incidence of CVD histories $(\mathrm{p}<0.001)$. 


\begin{tabular}{|c|c|c|c|c|c|c|c|c|}
\hline \multirow[t]{2}{*}{ Variables } & \multicolumn{2}{|c|}{ Total Cholesterol } & \multicolumn{2}{|c|}{ Triglyceride } & \multicolumn{2}{|c|}{ LDL-cholesterol } & \multicolumn{2}{|c|}{ HDL-cholesterol ${ }^{\star}$} \\
\hline & $\leq 200 \mathrm{mg} / \mathrm{dl}$ & $>200 \mathrm{mg} / \mathrm{dl}$ & $\leq 150 \mathrm{mg} / \mathrm{dl}$ & $>150 \mathrm{mg} / \mathrm{dl}$ & $\leq 100 \mathrm{mg} / \mathrm{dl}$ & $>100$ mg/dl & abnormal & normal \\
\hline \multicolumn{9}{|c|}{$\mathrm{N}(\%) \dagger$} \\
\hline $\mathrm{N}(\%)$ & 437 (59) & $302(41)$ & $349(47.3)$ & $390(52.7)$ & $327(44)$ & $413(56)$ & $93(12.6)$ & $93(12.6)$ \\
\hline Sex & $\begin{array}{l}\text { F: } 253(58) \\
\text { M:188 (62) }\end{array}$ & $\begin{array}{l}184(42) \\
114(38)\end{array}$ & $\begin{array}{l}217(62) \\
132(38)\end{array}$ & $\begin{array}{l}224(57.5) \\
166(42.5)\end{array}$ & $\begin{array}{l}197(60) \\
129(40)\end{array}$ & $\begin{array}{l}244(59) \\
169(41)\end{array}$ & $\begin{array}{l}37(40) \\
56(60)\end{array}$ & $\begin{array}{l}404(62) \\
242(38)^{1}\end{array}$ \\
\hline Smoking & $69(15.7)$ & $62(20.5)$ & $58(16.6)$ & $73(18.7)$ & $61(18.7)$ & $70(16,9)$ & $25(26.8)$ & $106(16.4)^{2}$ \\
\hline Alcohol intake ${ }^{\varphi}$ & $14(3.3)$ & $10(3.1)$ & $10(2.9)$ & $14(3.5)$ & $13(3.9)$ & $11(2.6)$ & $5(5.3)$ & $19(2.9)$ \\
\hline $\begin{array}{l}\text { Lipid lowering } \\
\text { drugs intake }\end{array}$ & $261(62)$ & $156(49)^{1}$ & $180(51.4)$ & $237(60.7)^{2}$ & $240(73)$ & $177(42)^{1}$ & $63(67)$ & $354(54.7)^{2}$ \\
\hline CAD history & $172(39.3)$ & $108(35.7)$ & $123(35.2)$ & $157(40.2)$ & $150(46)$ & $130(31.4)^{1}$ & $45(48.3)$ & $235(36.3)^{2}$ \\
\hline $\begin{array}{l}\text { Family history of } \\
\text { diabetes }\end{array}$ & $348(79.5)$ & $252(83.4)$ & $283(80.8)$ & $317(81.2)$ & $254(77.7)$ & $346(84.5)^{2}$ & $74(79.5)$ & $526(81.3)$ \\
\hline \multicolumn{9}{|c|}{ Mean \pm SD $\ddagger$} \\
\hline $\begin{array}{l}\text { Age } \\
\text { (year) }\end{array}$ & $54.5 \pm 6.2$ & $53.8 \pm 6.7$ & $54 \pm 6.7$ & $54.3 \pm 6.2^{2}$ & $53.7 \pm 6.4$ & $54.7 \pm 6.7$ & $54.1 \pm 6.4$ & $54.1 \pm 6.8$ \\
\hline $\begin{array}{l}\mathrm{BMI} \\
\left(\mathrm{kg} / \mathrm{m}^{2}\right)\end{array}$ & $29.1 \pm 4.6$ & $28.7 \pm 4.8$ & $29.2 \pm 4.8$ & $29.5 \pm 4.5$ & $29.1 \pm 4.5$ & $29.5 \pm 4.8$ & $28.7 \pm 4.1$ & $29.4 \pm 4.7$ \\
\hline $\begin{array}{l}\text { Physical activity } \\
\text { (Met.h/d) }\end{array}$ & $37.9 \pm 5.1$ & $37.5 \pm 5.8$ & $38 \pm 5$ & $37.5 \pm 5.8$ & $38.1 \pm 5.4$ & $37.5 \pm 5.5$ & $37.1 \pm 5.4$ & $37 / 8 \pm 5.4$ \\
\hline $\begin{array}{l}\text { Energy intake } \\
\text { (Kcal/d) }\end{array}$ & $2512 \pm 786$ & $2575 \pm 777$ & $2456 \pm 686$ & $2602 \pm 844^{2}$ & $2557 \pm 791$ & $2525 \pm 776$ & $2548 \pm 790$ & $2538 \pm 782$ \\
\hline
\end{tabular}

CAD (Coronary Artery Disease), BMI (Body Mass Index)

${ }^{*}$ Abnormal: $\leq 50 \mathrm{mg} / \mathrm{dl}$ for females, $\leq 40 \mathrm{mg} / \mathrm{dl}$ for males normal: $>50 \mathrm{mg} / \mathrm{dl}$ for females, $>40 \mathrm{mg} / \mathrm{dl}$ for males

fCurrent and former smokers

$\varphi$ consuming 1.5 ounces

${ }^{1} \mathrm{p}$ value $<0.001$ in each group

${ }^{2} \mathrm{p}$ value $<0.05$ in each group

Table 3: Characteristics of participants in terms of blood lipid profile

Our investigating on general characteristics of subjects in dietary patterns adherence quartiles shows those in the highest quartile of adherence healthy dietary pattern have higher energy intake and physical activity levels, compared to the lowest quartile $(\mathrm{p}=0.01)$. In contrast, highest quartile for unhealthy dietary pattern adherence had higher BMI, physical activity and energy intake compared to the lowest quartile (in all; $\mathrm{p}=0.01)$. They also had a lower mean age $(\mathrm{p}=0.01)$. Besides higher intake of alcohol was observed compared to lowest quartile $(\mathrm{p}=0.024)$.

The odds ratio of dyslipidemia in quartile of dietary patterns scores with adjustment for confounding variables has been shown in the two models (Table 4). In model 1 (without adjusting for variables) healthy dietary pattern adherence was significantly associated with low levels of LDL-c and high HDL-c levels. After adjustment for confounding factors, the association between the healthy dietary pattern and LDL-c and HDL-c level still remained significant. Comparing to the first quartile of healthy food patterns, individuals with highest score had lower odds ratio for having high $\mathrm{LDL}-\mathrm{c}(\mathrm{OR}=0.45,95 \% \mathrm{CI}=0.28-7.2)$. Also having high HDL-c in the highest adherence to this pattern was 2.4 times higher than those in the lowest adherence of this group (OR=2.4, 95\% CI =1.1-5.1). Adherence to Unhealthy dietary pattern no significant relationship was observed in two models (without and after adjusting for variables).

\section{Discussion}

According to the study results, after cofounder adjustment, the most adherences to healthy food pattern decreases the risk of having high LDL by 55\%. Also the chance of increased HDL-c in the highest adherence quartile of the pattern is 2.4 times higher than those in the lowest quartile of the group.

As Asian population has different dietary styles and habits and in spite of the fact most information about the association between food patterns and risk of dyslipidemia is mainly derived from studies investigated Western, European or U.S. populations. It is not clear in what extent these findings are applicable in populations around the world [37]. Moreover in this case, no specific study has been done on diabetic populations. However several studies evaluated dietary pattern role on the metabolic syndrome prevalence. As the diabetic patients are told and learnt to obey specific diet, we investigated their dietary patterns role on risk of hyperlipidemia. 


\begin{tabular}{|c|c|c|c|c|c|c|c|}
\hline \multicolumn{8}{|c|}{ Score quartiles of dietary patterns } \\
\hline Risk factor ${ }^{*}$ & & & 1 st & 2th & 3th & 4th & P value $\dagger$ \\
\hline \multicolumn{8}{|c|}{ OR(95\% CI) } \\
\hline & Healthy & model $1 \ddagger$ & 1.0 & $1.25(0.8-1.9)$ & $1.13(0.7-1.7)$ & $0.94(0.6-1.4)$ & 0.79 \\
\hline Total & pattern & model $2 \$$ & 1.0 & $1.36(0.87-2.1)$ & $1.15(0.73-1.8)$ & $0.92(0.59-1.4)$ & 0.71 \\
\hline \multirow[t]{3}{*}{ Cholesterol } & Unhealthy & model $1 \neq$ & 1.0 & $0.47(0.3-0.72)$ & $0.79(0.52-1.1)$ & $0.82(0.54-1.2)$ & 0.6 \\
\hline & pattern & model $2 \$$ & 1.0 & $0.36(0.21-0.60)$ & $0.66(0.41-1.0)$ & $0.72(0.46-1.1)$ & 0.16 \\
\hline & Healthy & model $1 \neq$ & 1.0 & $1.36(0.9-2.0)$ & $1.12(0.74-1.7)$ & $1.1(0.73-1.6)$ & 0.6 \\
\hline \multirow[t]{4}{*}{ Triglyceride } & pattern & model $2 \$$ & 1.0 & $1.6(1.0-2.5)$ & $1.35(0.86-2.1)$ & $1.1(0.77-1.8)$ & 0.4 \\
\hline & Unhealthy & model $1 \ddagger$ & 1.0 & $0.71(0.47-1.08)$ & $0.90(0.59-1.36)$ & $0.90(0.59-1.36)$ & 0.6 \\
\hline & pattern & model $2 \$$ & 1.0 & $0.88(0.53-1.4)$ & $1.0(0.65-1.6)$ & $0.96(0.61-1.5)$ & 0.8 \\
\hline & Healthy & model $1 \ddagger$ & 1.0 & $0.91(0.60-1.3)$ & $1.0(0.66-1.5)$ & $0.61(0.40-0.93)$ & 0.024 \\
\hline \multirow[t]{5}{*}{ LDL-c } & pattern & model $2 \$$ & 1.0 & $0.63(0.39-1.0)$ & $0.76(0.47-1.2)$ & $0.45(0.28-7.2)$ & 0.001 \\
\hline & Unhealthy & model $1 \neq$ & 1.0 & $1.0(0.68-1.56)$ & $0.84(0.62-1.2)$ & $1.3(0.88-2.04)$ & 0.16 \\
\hline & pattern & model $2 \$$ & 1.0 & $1.0(0.64-1.5)$ & $0.85(0.53-1.3)$ & $1.4(0.86-2.5)$ & 0.15 \\
\hline & Healthy & model $1 \ddagger$ & 1.0 & $1.0(0.56-1.7)$ & $1.3(0.63-2.4)$ & $2.1(1.1-4.3)$ & 0.024 \\
\hline & pattern & model $2 \$$ & 1.0 & $0.96(0.53-1.7)$ & $1.4(0.76-2.7)$ & $2.4(1.1-5.1)$ & 0.020 \\
\hline \multirow[t]{2}{*}{ HDL-c } & Unhealthy & model $1 \ddagger$ & 1.0 & $0.52(0.26-0.1)$ & $0.8(0.3-1.1)$ & $0.54(0.27-1.02)$ & 0.071 \\
\hline & pattern & model $2 \$$ & 1.0 & $0.53(0.26-1.01)$ & $0.59(0.28-1.2)$ & $0.48(0.21-1.02)$ & 0.071 \\
\hline
\end{tabular}

${ }^{\star}$ Total cholesterol: $>200 \mathrm{mg} / \mathrm{dl}$, Triglyceride: $>150 \mathrm{mg} / \mathrm{dl}$, LDL-c: $>100 \mathrm{mg} / \mathrm{dl}, \mathrm{HDL}-\mathrm{c}: \leq 50 \mathrm{mg} / \mathrm{dl}$ for females, $\leq 40 \mathrm{mg} / \mathrm{dl}$ for males $\dagger \mathrm{p}$ value based on comparison of the first quartile (baseline) and the fourth quartile †Unadjusted (crude)

$\$$ Adjusted for age, gender, family history of diabetes, duration of diabetes, body mass index, physical activity, energy intake and lipidlowering drugs intake

Table 4: Odds ratios and 95\% confidence interval of dyslipidemia according to score quartiles of dietary patterns in the study population

Two major food patterns, Healthy and Unhealthy dietary patterns were identified in this cross sectional survey. Dietary patterns obtained in this study are similar to the study on Tehran North-East women [49]. Other similar studies in Iran, presented three major dietary patterns $[50,51]$ which Western and Healthy dietary pattern of these studies were resemble to our Unhealthy and Healthy patterns respectively. Although dietary patterns among countries and cultures are different and not comparable, Unhealthy and Healthy food patterns in our study have resemble to those studied patterns in the world [14,15,31-34].

Healthy pattern obtained in this study is consistent with the findings of Ismail-Zadeh and colleagues [39] on female teachers in Tehran in which those in the highest quintile of the healthy dietary pattern (high intake of fruits, vegetables, tomatoes, poultry, beans and green leafy vegetables, tea, juice and whole grain) had lower odds for dyslipidemia. Healthy dietary pattern in Finnish adults in Mikkila, et al. [33] showed on longitudinal analysis, LDL-c concentration was inversely correlated with score of Healthy dietary pattern (high intake of vegetables, beans and nuts, tea, rye, cheese and other dairy products). In Asian population several studies have shown lower likelihood of having low HDL-c and/or lower risk of having high TG [27-29]. The protective effect of these dietary patterns can be explained by healthy components (such as vegetables, fruits, fish and whole grains). However Denova-Gutierrez [34] examined major dietary patterns relation to risk of metabolic syndrome. Prudent dietary pattern in this study, consistent with our Healthy pattern, no significant association was observed between this dietary pattern and metabolic syndrome components. Similar to this finding Akter in Japanese working population [35] and Naja in Lebanese adults [36] found no association between dietary patterns and the chance of having high LDL-c or low HDL-c. These confliction may suggest other environmental and clinical factors besides dietary factors in controlling lipid levels.

Besides Traditional dietary pattern of Ismail-Zadeh study (high intake of refined grains, potatoes, tea, whole grains, hydrogenated fats, beans and broth) were significantly associated with higher odds of dyslipidemia. Amini, et al. [30] studied patients with glucose intolerance expressed Western dietary pattern (high intake of sweets, butter, soft drinks, mayonnaise, sugar, cakes, meat , hydrogenated fats and eggs) is associated with a high chance of increasing triacylglycerol.

"Sweets" dietary patterns in Noel, et al. [31], Traditional dietary pattern in Mikkila [33], processed food products pattern in Olinto, et al. [34] also observed that pattern of were positively associated with high LDL-c and/or low HDL-c concentrations. These patterns were similar to our Unhealthy pattern in high consumption of snacks, sweets and sugar, fast foods, animal fat rich foods. Studies on Asian population, Song shows [28] traditional pattern (high consumption of white rice and kimchi) an increased risk of having low HDL-c compared with the other two patterns. The rice oriented pattern of Song [40] was positively associated with hypertriglyceridemia in men and LDL-c in both men and women. This pattern was characterized by a high intake of white rice but low intake of vegetables, fruits, meat, and dairy products. These patterns are somehow comparable with our Unhealthy pattern in high consumption of refined grains. However Cho, et al. [27] study in Korean women shows higher HDL-cholesterol levels in the 
participants with the highest Western dietary pattern score. Western pattern was identified by high intake of fast foods, animal rich fat foods, fried foods, grilled meat and seafoods, sweet foods, resemble to Unhealthy pattern in current study. Taking all the studies, consumption of refined grains, sweets, sugar, butter and animal fat rich foods can increase the risk of having dyslipidemia. However we found no relation between unhealthy dietary patterns with lipid disorders.

The Cross-sectional nature of the study does not allow cause and effect conclusions. Findings obtained should be confirmed in prospective studies. On the other hand, the assessing dietary intake using a food frequency questionnaire, it is likely to have measurement error such as difficulties in recalling consumed items, under-reporting or over-reporting about some or total number of food items. In the current study, dietary patterns were assessed only upon dietary intake. However, some researchers rely on FFQ as dietary assessment instrument, nutritional behavior such as eating habits and timing and frequency of meals and snacks should be noticed [52]. Another limitation, there is no gold standard to determine the number of factors in factor analysis, and final decision to determine the number of factors to be realized is up to investigator. However the reliability and validity of this method has been shown in several studies [17,53]. Most of our participated individuals were over weighted (83.3\%) and also 37.9\% have CAD history, so make the judgment somehow blurred. Moreover high number of our participant were under lipid-lowering treatments, despite this factor was adjusted in analysis; we could not identify the intensity of treatment since it is a critical factor that influence lipid profile.

Overall, the findings suggest that a dietary pattern rich in vegetables, fruits, fish, beans and olives is associated with a lower risk of developing high LDL-c levels and lower chance of having low HDL-c in diabetic patients. Yet the results obtained should be confirmed in prospective and interventional studies in healthy diabetic population with normal weight.

\section{Acknowledgments}

We are particularly grateful to all participants in the study for their dedication and contribution to the research.

\section{Funding}

This study was supported by Tehran University of Medical Sciences Grant. It's part of the research, 90-03-27-15060, held in Tehran University of Medical Sciences.

\section{References}

1. Perez-Martinez P, Lopez-Miranda J, Perez-Jiminez F, Ordovas JM (2008) Influence of genetic factors in the modulation of postprandial lipemia. Atheroscler Suppl 9: 49-55.

2. Wallace AM, McMahon AD, Packard CJ, Kelly A, Shepherd J, et al. (2001) Plasma leptin and the risk of cardiovascular disease in the West of Scotland Coronary Prevention Study (WOSCOPS). Circulation 104: 3052-8.

3. Meigs JB, Nathan DM, D’Agostino RB, Wilson PW, Framingham Offspring Study (2002) Fasting and postchallenge glycemia and cardiovascular disease risk: the Framingham Offspring Study. Diabetes Care 25: 1845-50.

4. Barr EL, Zimmet PZ, Welborn TA, Jolley D, Magliano DJ, et al. (2007) Risk of cardiovascular and all-cause mortality in individuals with diabetes mellitus, impaired fasting glucose, and impaired glucose tolerance: the Australian Diabetes, Obesity, and Lifestyle Study (AusDiab). Circulation 116: 151-7.

5. Mahan KL, Stump ES, Raymond JL (2012) Krause's Food, Nutrition \& Diet therapy. 13th ed: Saunders.

6. Gordon DJ (1998) Factors affecting high-density lipoproteins. Endocrinol Metab Clin North Am 27: 699-709.

7. Alberti KG, Zimmet P, Shaw J (2007) International Diabetes Federation: a consensus on Type 2 diabetes prevention. Diabet Med 24: 451-63.

8. Goff DC, Bertoni AG, Kramer H, Bonds D, Blumenthal RS, et al. (2006) Dyslipidemia prevalence, treatment, and control in the Multi-Ethnic Study of Atherosclerosis (MESA): gender, ethnicity, and coronary artery calcium. Circulation 113: 647-56.

9. Vessby B (2000) Dietary fat and insulin action in humans. Br J Nutr 83: 91-6.

10. Visiolo F, Borsani L, Galli C (2000) Diet and prevention of coronary heart disease: the potential role of phytochemicals. Cardiovasc Res 47: 419-25.

11. Storlien LH, Baur LA, Kriketos AD, Pan DD, Cooney GJ, et al. (1996) Dietary fats and insulin action. Diabetologia 39: 621-31.

12. Salmeron J, Manson JE, Stampfer MJ, Colditz GA, Wing AL, et al. (1997) Dietary fiber, glycemic load, and risk of non-insulin-dependent diabetes mellitus in women. JAMA 277: 472-7.

13. Connor WE (2000) Importance of $n-3$ fatty acids in health and disease. Am J Clin Nutr 71: 171S-5S.

14. Fung TT, Rimm EB, Spiegelman D, Rifai N, Tofler GH, et al. (2001) Association between dietary patterns and plasma biomarkers of obesity and cardiovascular disease risk. Am J Clin Nutr 73: 61-7.

15. Hu FB, Rimm EB, Stampfer MJ, Ascherio A, Spiegelman D, et al. (2000) Prospective study of major dietary patterns and risk of coronary heart disease in men. Am J Clin Nutr 72: 912-21.

16. Hu FB (2002) Dietary pattern analysis: a new direction in nutritional epidemiology. Curr Opin Lipidol 13: 3-9.

17. Hu FB, Rimm E, Smith-Warner SA, Feskanich D, Stampfer MJ, et al. (1999) Reproducibility and validity of dietary patterns assessed with a food frequency questionnaire. Am J Clin Nutr 69: 243-9.

18. Jacques PF, Tucker KL (2001) Are dietary patterns useful for understanding the role of diet in chronic disease? Am J Clin Nutr 73: 1-2.

19. Newby PK, Tucker KL (2004) Empirically derived eating patterns using factor or cluster analysis: a review. Nutr Rev 62: 177-203.

20. Slattery M (2008) Defining dietary consumption: is the sum greater than its parts? Am J Clin Nutr 88: 14-5. 
21. Martinez-Gonzalez MA, Bes-Rastrollo M, Serra-Majem L, Lairon D, Estruch R, et al. (2009) Mediterranean food pattern and the primary prevention of chronic disease: recent developments. Nutr Rev 67: 111-6.

22. Tzima N, Pitsavos C, Panagiotakos DB, Skoumas J, Zampelas A, et al. (2007) Mediterranean diet and insulin sensitivity, lipid profile and blood pressure levels, in overweight and obese people; The Attica study. Lipids in Health Dis 6: 22.

23. Wirfält E, Hedblad B, Gullberg B, Mattisson I, Andrén C, et al. (2001) Food Patterns and Components of the Metabolic Syndrome in Men and Women: A Cross-sectional Study within the Malmö Diet and Cancer Cohort. Am J Epidemiol 154: 1150-9.

24. Jacobs DR Jr, Steffen LM (2003) Nutrients, foods, and dietary patterns as exposures in research: a framework for food synergy. Am J Clin Nutr 78: 508S-13S.

25. Panagiotakos DB, Pitsavos C, Skoumas Y, Stefanadis C (2007) The association between food patterns and the metabolic syndrome using principal components analysis: the ATTICA study. J Am Diet Assoc 107: 979-87.

26. Sonnenberg L, Pencina M, Kimokoti R, Quatromoni P, Nam BH, et al. (2005) Dietary patterns and the metabolic syndrome in obese and non-obese Framingham women. Obes Res 13: 153-62.

27. Cho YA, Kim J, Cho ER, Shin A (2011) Dietary patterns and the prevalence of metabolic syndrome in Korean women. Nutr Metab Cardiovasc Dis 21: 893-900.

28. Song Y, Joung H (2012) A traditional Korean dietary pattern and metabolic syndrome abnormalities. Nutr Metab Cardiovasc Dis 22: 456-62.

29. Kim J, Jo I (2011) Grains, Vegetables, and Fish Dietary Pattern Is Inversely Associated with the Risk of Metabolic Syndrome in South Korean Adults. J Am Diet Assoc 111: 1141-9.

30. Amini M, Esmaillzadeh A, Shafaeizadeh S, Behrooz J, Zare M (2010) Relationship between major dietary patterns and metabolic syndrome among individuals with impaired glucose tolerance. Nutrition 26: 986-92.

31. Noel SE, Newby PK, Ordovas JM, Tucker KL (2009) A Traditional Rice and Beans Pattern Is Associated with Metabolic Syndrome in Puerto Rican Older Adults. J Nutr 139: 1360-7.

32. Denova-Gutiérre E, Castañón S, Talavera JO, Gallegos-Carrillo K, Flores M, et al. (2010) Dietary Patterns Are Associated with Metabolic Syndrome in an Urban Mexican Population. J Nutr 140: 1855-63.

33. Mikkilä V, Räsänen L, Raitakari OT, Marniemi J, Pietinen P, et al. (2007) Major dietary patterns and cardiovascular risk factors from childhood to adulthood. The Cardiovascular Risk in Young Finns Study. Br J nutr 98: 218-25.

34. Olinto MT, Gigante DP, Horta B, Silveira V, Oliveira I, et al. (2011) Major dietary patterns and cardiovascular risk factors among young brazilian adults. Eur J Nutr 51: 281-91.

35. Akter S, Nanri A, Pham NM, Kurotani K, Mizoue T (2013) Dietary patterns and metabolic syndrome in a Japanese working population. Nutrition \& Metabolism 10: 30 .

36. Naja F, Nasreddine L, Itani L, Adra N, Sibai AM, et al. (2013) Association between dietary patterns and the risk of metabolic syndrome among Lebanese adults. Eur J Nutr 52: 97-105.

37. Akesson A, Weismayer C, Newby PK, Wolk A (2007) Combined effect of lowrisk dietary and lifestyle behaviors in primary prevention of myocardial infarction in women. Arch Intern Med 167: 2122-7.

38. Esmaillzadeh A, Kimiagar M, Mehrabi Y, Azadbakht L, Hu FB, et al. (2007) Dietary patterns, insulin resistance, and prevalence of the metabolic syndrome in women. Am J Clin Nutr 85: 910-8.

39. Haghighatdoost F, Zaribaf F, Azadbakht L, Esmaillzadeh A (2012) Association between major dietary patterns and risk factors for cardiovascular disease among women. Iranian J Nutr Sci \& Food Tec 7: 19-30.

40. Song S, Lee J, Paik H, Park M, Song Y (2012) Dietary patterns based on carbohydrate nutrition are associated with the risk for diabetes and dyslipidemia. Nutr Res Pract 6: 349-56.

41. WHO (2008) Waist Circumference and Waist-Hip Ratio: Report of a WHO Expert Consultation. GenevaDecember.

42. Mirmiran P, Esfahani F, Azizi F (2009) [Arzyabi ravaie nesbi va payaie porseshnameye basamad masrafe ghazaie baraye barasi daryafthaye mavade ghazaie:motaleye ghand va lipid iran]. Iranian Journal of Diabetes and Lipid 9: 185-97.

43. Rimm EB, Giovannucci EL, Stampfer MJ, Colditz GA, Litin LB, et al. (1992) Reproducibility and validity of an expanded self administered semi quantitative food frequency questionnaire among male health professionals. Am J Epidemiol 135: 1114-26.

44. Ghaffarpour M, Houshyar-Rad A, Kianfar H (1999) The manual for household measures, cooking yields factors and edible portion of food. Tehran: Keshavarzi press.

45. Azizi F, Rahmani M, Ghanbarian A, Emami H, Salehi P, et al. (2003) Serum lipid levels in an Iranian adults population: Tehran Lipid and Glucose Study. Eur J Epidemiol 18: 311-9.

46. Association AD (2014) Standards of Medical Care in Diabetes-2014. Diabetes Care. January 37(SUPPLEMENT 1).

47. Aadalh M, Jorgensen T (2003) Validation of a new self-repot instrument for measuring physical activity. Med Sci Sports Exerc 35: 1196-202.

48. Kelishadi R, Rabiei K, Khosravi A, Famouri F, Sadeghi M, et al. (2007) Assessment of Physical Activity of Adolescents in Isfahan. J Shahrekord Univ Med Sci 3: 27-33.

49. Rezazadeh A, Rashidkhani B (2010) The association of general and central obesity with major dietary patterns in adult women living in Tehran, Iran. J Nutr Sci Vitaminol 56: 132-8.

50. Esmaillzadeh A, Azadbakht L (2008) Major dietary patterns in relation to general obesity and central adiposity among Iranian women. J Nutr 138: 358-63.

51. Mirmiran P, Djazayery A, Hosseini esfahani F, Mehrabi Y, Azizi F (2008) Change in food patterns of Tehrani adults and its association with changes in their body weight and body mass index in District 13 of Tehran: Tehran Lipid and Glucose Study. Iranian J Nutr Sci \& Food Tec 2: 67-80.

52. Tseng M (1999) Validation of dietary patterns assessed with a food frequency questionnaire. Am J Clin Nutr 70: 422-31.

53. Weismayer C, Anderson JG, Wolk A (2006) Changes in the Stability of Dietary Patterns in a Study of Middle-Aged Swedish Women. J Nutr 136: 1582-7. 


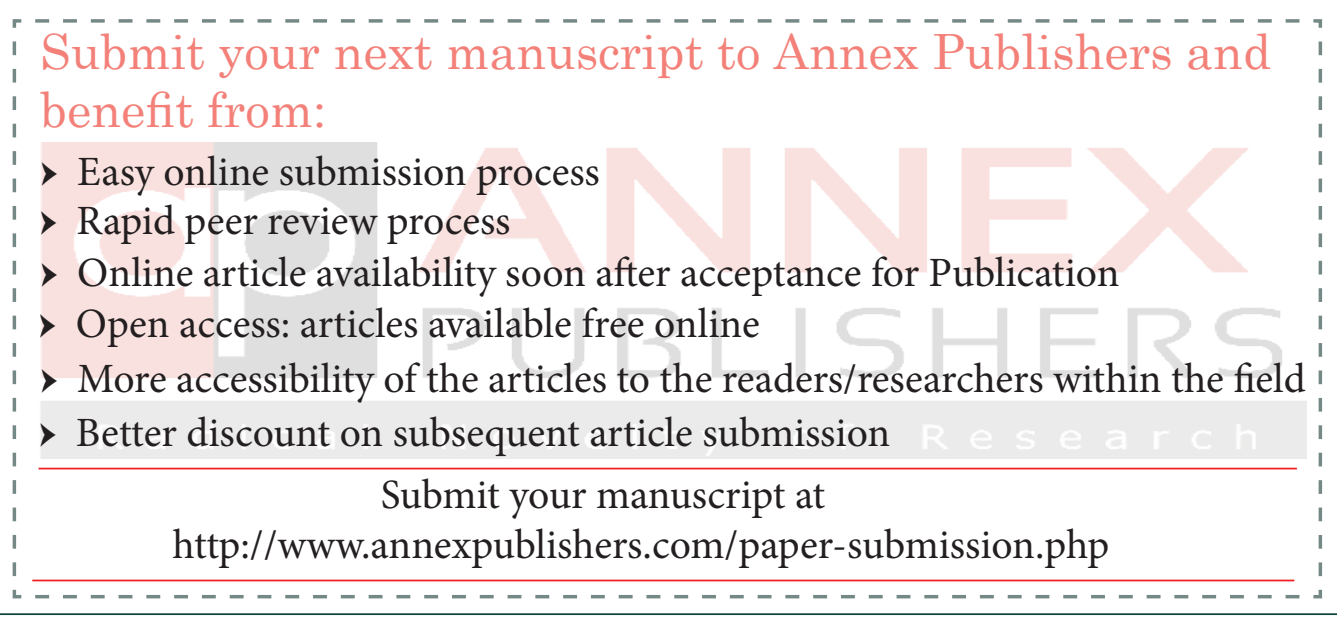

